\title{
Desafios da Reforma Psiquiátrica no Brasil
}

BENILTON BEZERRA JR."

Com a virada do século, a Reforma Psiquiátrica no Brasil deixou definitivamente a posição de "proposta alternativa" e se consolidou como o marco fundamental da política de assistência à saúde mental oficial. Mais do que isso, a influência do seu ideário vem-se expandindo no campo social, no universo jurídico e nos meios universitários que formam os profissionais de saúde. Apesar das conhecidas dificuldades enfrentadas pelo sistema de saúde pública no Brasil, é fato que o cenário psiquiátrico brasileiro vem mudando a olhos vistos. Os mais de mil Centros de Atenção Psicossocial (CAPS) espalhados pelo país vêm modificando fortemente a estrutura da assistência à saúde mental. A rede composta por este tipo de equipamento vem substituindo progressivamente o modelo hospitalocêntrico e manicomial, de características excludentes, opressivas e reducionistas. Em seu lugar vem sendo construído um sistema de assistência orientado pelos princípios fundamentais do Sistema Único de Saúde (universalidade, eqüidade e integralidade), acrescido da proposta de desinstitucionalização - cujo alcance ultrapassa os limites das práticas de saúde e atinge o imaginário social e as formas culturalmente validadas de compreensão da loucura.

No entanto, a própria consolidação da Reforma vem trazendo à tona uma quantidade crescente de desafios que precisam ser incorporados à agenda dos campos da Saúde Mental e da Saúde Coletiva. Não há precedente de implantação de uma reforma deste tipo num país com as características (geográficas, políticas, sociais) do Brasil. A construção de um sistema assistencial, um imaginário cultural e uma rede de laços sociais inspirados nos ideais da Reforma exige que a imaginação, a criatividade e a reflexão crítica encontrem uma maneira de delinear com clareza quais são os desafios específicos que este horizonte de transformação enfrenta nas condições de nosso país.

Sendo uma proposição de mudança paradigmática - e não apenas mais uma proposta de modelo assistencial -, a Reforma Psiquiátrica se desdobra em 
vários planos, situados em diversos campos. No plano assistencial, trata-se de pensar não apenas formas inovadoras de organização da atenção, mas também modelos de cuidado e intervenção adequados aos novos dispositivos - muito diferentes tanto dos ambientes hospitalares quanto dos espaços ambulatoriais tradicionais, e aos novos objetivos - mais abrangentes que os da clínica individual tradicional. Além disso, num país como o Brasil, de dimensões continentais e enorme diversidade cultural, não é possível construir um modelo assistencial que sirva igualmente para as megalópoles e as pequenas cidades do interior, para grandes concentrações populacionais e regiões de população escassa, como em certas áreas amazônicas. As noções de rede e território, por exemplo, que são centrais às proposições da Reforma, não podem ser pensadas de forma idêntica em contextos socioculturais tão diferentes como os pequenos municípios do interior do Nordeste e os imensos bairros de São Paulo ou Belo Horizonte.

$\mathrm{Na}$ esfera da clínica (uma dimensão, mas não a única, do plano assistencial), os desafios apontam para duas direções: de um lado, é preciso avançar na elaboração de dispositivos teóricos e de formas de ação que ao mesmo tempo retenham o horizonte fundamental da clínica (a ampliação da capacidade normativa psíquica, existencial e social do sujeito) e amplie o alcance da rede (a constituição de uma clínica ampliada, a incorporação de várias categorias profissionais às estratégias terapêuticas, o recurso a modalidades de intervenção oriundas de diversas orientações teóricas, etc.). Esse tipo de discussão é, por assim dizer, interior ao campo da Reforma.

De outro lado, existe o debate com os adversários. O sucesso do movimento da Reforma pode ser medido em parte pelo fato de que ninguém mais resiste abertamente ao ideário antimanicomial. Mesmo os defensores dos hospitais psiquiátricos que tentam reverter os dispositivos legais e as articulações políticas que sustentam o novo cenário psiquiátrico no país afirmam estar de acordo com as diretrizes gerais do movimento transformador da assistência, centrando suas críticas e reivindicações no que apresentam como insuficiências ou inconsistências do novo modelo assistencial.

A resistência às propostas reformistas aparece de forma indireta, na defesa da hegemonia absoluta dos médicos no campo da atenção à saúde, na ênfase nos tratamentos biológicos como única forma efetiva de tratamento, na importação acrítica, para a Psiquiatria, do modelo da medicina baseada em evidências, no abuso na utilização da nosografia descritiva dos DSMs, em detrimento da atenção às dimensões psicodinâmica, fenomenológica e 
psicossocial das psicopatologias, e assim por diante. Deste modo, o embate que nos primeiros anos se centrava na busca de espaços dentro do sistema políticoassistencial hoje tende a girar em torno de debates fortemente marcados por questões de natureza epistemológica, teórica e ética.

Ainda no plano assistencial, há uma dimensão política importante, que se manifesta no esforço de consolidação do poder de indução que os órgãos de coordenação da atenção à saúde mental precisam exercer para estimular transformações nas práticas assistenciais, tanto na rede pública quanto na rede privada. Isto implica defender mecanismos e critérios de financiamento que reforcem as propostas da Reforma - como a construção de redes territoriais de assistência, o estímulo a dispositivos do tipo CAPS, a implantação de programas de moradia e assim por diante.

A indução desse tipo de mudança, no entanto, exige que tenhamos como avaliar seu impacto, e ainda não dispomos de modelos de avaliação adequados às necessidades da saúde mental, que não pode ser avaliada com base nos mesmos critérios e medidas utilizados na clínica médica e na saúde pública. Na atenção ao sofrimento psíquico, é preciso encontrar formas de estimar subjetivamente, e não apenas medir objetivamente, os resultados das estratégias terapêuticas. O estabelecimento de critérios de avaliação consensualmente aceitos tornou-se hoje um fator crucial de sustentação do movimento da Reforma.

A formação de recursos humanos é outro desafio fundamental. A maior parte dos novos profissionais da rede é formada de jovens que não passaram pelo processo de luta política e ideológica que envolveu a criação do movimento antimanicomial, não viveram o intenso intercâmbio com figuras emblemáticas desse movimento no nível internacional, como Basaglia, Foucault, Rotelli e outros, em suas vindas ao Brasil. Boa parte desses profissionais se tornou adulta num momento da vida do país em que as grandes bandeiras de transformação política já tinham se tornado história, momento em que a própria esfera da política começou a experimentar um esvaziamento que só fez se acentuar desde então.

Para a primeira geração de profissionais envolvida na construção da Reforma, o pano de fundo político e ideológico em que esta construção se dava era claro, até porque ele abarcava várias outras áreas da vida social, como a luta contra os resquícios do regime militar e os movimentos reivindicatórios de setores sociais. O reflexo, junto aos novos profissionais, do esmaecimento da 
política, e a hegemonia crescente do discurso técnico tornam a formação desses profissionais uma tarefa complexa, pois se de um lado é preciso dar-lhes uma formação teórica e técnica sólida, de outro é necessário que ela suscite uma vocação crítica e criativa, de modo a atender aos desafios que um processo de transformação contínuo, como a Reforma, impõe de modo constante. Isto implica não apenas o entendimento e a colocação em prática das políticas e modelos propostos, como também a possibilidade de auto-reflexão, de reavaliação constante do impacto que o trabalho cotidiano nas atividades assistenciais exerce sobre a própria subjetividade - única forma de combater os insidiosos "manicômios mentais", muito mais resistentes à mudança justamente por não serem objetivos, e sim enraizados em padrões cognitivos e pautas afetivas profundamente internalizadas.

As novas formas de organização das equipes, a transformação dos papéis destinados aos técnicos, o trabalho interdisciplinar e intersetorial, a articulação entre os aspectos clínicos e políticos da atenção psicossocial, o entrelaçamento entre estratégias de cuidado e estratégias de responsabilização ou interpelação do sujeito, todos esses são temas cruciais para a formação de profissionais capazes de levar adiante o processo de transformação defendido pelo ideário reformista.

Nos planos jurídico e político, a temática dos direitos humanos e da defesa da dignidade da pessoa, presente desde o início dos movimentos de contestação da cultura manicomial, tem sido acrescida de iniciativas que avançam na discussão dos direitos civis e sociais dos portadores de transtornos mentais. Talvez a característica mais importante do debate atual seja o deslocamento progressivo do centro de gravidade da discussão, que vem deixando de ser uma defesa dos mecanismos de proteção jurídica a pessoas com déficit ou perturbação (trabalho protegido, pensão protegida), para se constituir numa discussão sobre mecanismos jurídicos que possibilitem a inclusão civil e social de pessoas com características especiais (formas de contratualidade, mecanismos de responsabilização) e ampliação de sua autonomia. Em outras palavras, o debate ultrapassa os limites da argumentação médica e se insere progressivamente no debate político acerca da inserção no campo da cidadania.

No plano sociocultural, o desafio é fazer da loucura e do sofrimento psíquico uma questão que ultrapasse as fronteiras do discurso técnico, e do saber psiquiátrico em especial, insistindo na dimensão existencial e humana que facilmente se esconde por trás dos jargões e protocolos médico-psicológicos, trazendo para o debate público do tema atores de diversos segmentos sociais. 
Várias iniciativas bem-sucedidas têm sido realizadas neste sentido no país, tanto a partir das próprias unidades assistenciais (participação de blocos organizados nos CAPS nos carnavais, presença de grupos musicais em eventos da cidade, etc.), quanto fora delas. Filmes como Bicho de sete cabeças (2001), de Laiz Bodanski, e Estamira (2004), de Marcos Prado, matérias jornalísticas sobre a transformação de manicômios (como o de Barbacena) são exemplos de como a arte e o jornalismo se tornaram atores fundamentais no processo de sustentação social do ideário da Reforma.

Mais do que buscar a aceitação de uma nova política assistencial, o desafio nesse campo é produzir uma nova sensibilidade cultural para com o tema da loucura e do sofrimento psíquico. Trata-se de promover uma desconstrução social dos estigmas e estereótipos vinculados à loucura e à figura do doente mental, substituindo-os por um olhar solidário e compreensivo sobre a diversidade e os descaminhos que a experiência subjetiva pode apresentar, olhar fundado numa atitude de respeito, tolerância e responsabilidade com aqueles que se encontram com sua normatividade psíquica restringida.

Os três artigos que se seguem retomam, cada um a seu modo, esses desafios como tema de reflexão. Em "Rodas de conversa sobre o trabalho na rua: discutindo saúde mental", Izabel Cristina Rios descreve uma experiência realizada na periferia de São Paulo com agentes comunitários de saúde integrados ao Programa de Saúde da Família. Esses profissionais estão na ponta da atenção à saúde mental, e sua atuação pode ser decisiva, não só no encaminhamento precoce e bem-feito de situações clínicas que exijam atendimento especializado - casos de psicose, perturbações pós-parto, autismo infantil, etc. - como também na imensa maioria das situações de sofrimento psíquico em que uma intervenção sensível e cuidadosa pode abrir caminhos para soluções que não necessariamente envolvam tratamento especializado, reduzindo muito o processo de patologização e medicalização que o sistema de saúde formal tende a estimular.

Os agentes comunitários ocupam uma posição especial, na interface entre o campo médico e a vida social, entre o discurso competente e a sabedoria popular, entre a ação técnica e a mobilização de recursos da própria comunidade, e com isto se habilitam a exercer papel fundamental no cuidado do sofrimento psíquico. Para que possam dar conta desse desafio, é preciso dar-lhes mais do que uma formação técnica bem-feita - conceitos e práticas básicas em saúde mental. É necessário que se ofereça a eles a possibilidade de uma formação 
continuada, que envolva não apenas o ensino formal, mas também a análise dos casos e situações atendidas que possibilite uma discussão sobre como sua própria subjetividade intervém e é afetada em sua prática cotidiana, situando o centro de sua atuação no espaço relacional, na trama interpessoal, na rede de lugares que compartilham com a população atendida.

O essencial da experiência relatada no artigo é a valorização de um aspecto cuja importância quase nunca é reconhecida: o cuidado para com os profissionais e a transformação de sua experiência em fonte preciosa de informação para a gestão e a formulação de propostas de atenção. Essa valorização resulta numa profunda mudança no papel exercido por esses profissionais, que passam a ocupar o lugar (e sentirem a importância de serem) protagonistas, e não apenas auxiliares, nas estratégias de atenção à saúde. A riqueza do trabalho ultrapassa em muito as fronteiras dos programas de saúde da família, sendo de interesse para todos os níveis dos programas de saúde mental.

O artigo "Modos de subjetivação dos trabalhadores de saúde mental em tempos de Reforma Psiquiátrica", de Henrique Caetano Nardi e Tatiana Ramminger, também aborda o papel dos trabalhadores na psiquiatria da Reforma, insistindo na tese de que os modos de subjetivação dos profissionais que militam nos novos dispositivos jogam um papel decisivo na sustentação e no aprofundamento das propostas reformistas. Isto é exigido pela própria natureza das propostas, que não se restringem a modificações de ordem técnica ou organizacional, girando, na verdade, em torno da construção social de uma nova relação com a loucura e o sofrimento mental.

Neste sentido, os autores descrevem um deslizamento histórico desta relação, que passou do modelo religioso da salvação do louco (no período colonial) para o modelo médico da cura e do reparo (a partir do fim do século XIX), para chegar às proposições reformistas que buscam uma superação deste modelo, não por uma recusa romântica do sofrimento provocado pela loucura, mas pela insistência na inclusão das formas de atenção fundadas no paradigma do cuidado (e não apenas na busca da cura) e na ancoragem das estratégias assistenciais e culturais de confronto com a loucura no processo mais geral de ampliação do exercício da cidadania. Ora, isto implica a existência de profissionais de saúde mental capazes de levar em conta esta característica especial da psiquiatria: a de ser um campo essencialmente atravessado por determinantes biológicos, influências culturais, jogos de verdade, paradigmas teóricos, dinâmicas sociais, lutas econômicas e seus reflexos político-assistenciais, e assim por diante. 
Em suma, o desafio imposto pela Reforma exige a formação de profissionais dotados de capacidade de reflexão crítica - elemento indispensável para a superação das imensas dificuldades inerentes ao trabalho (desvalorização do servidor público, investimentos aquém do necessário) - e para a sustentação de uma prática de cuidado que se constitua como um exercício de transformação para todos os envolvidos: pacientes, profissionais e as redes sociais em volta deles. Só isto permite manter a esperança de construção de uma nova atitude epistemológica e ética frente ao fenômeno da loucura.

É justamente a natureza das premissas éticas existentes na proposta de desinstitucionalização - elemento nuclear da Reforma - que Maria Gabriela Godoy e Maria Lúcia Bosi apresentam e discutem em "A alteridade no discurso da Reforma Psiquiátrica brasileira face à ética radical de Lévinas". Em seu artigo, as autoras põem o centro de gravidade da desinstitucionalização na idéia de desconstrução e na concepção de alteridade, que elas analisam a partir de uma reflexão sobre a ética radical encontrada na obra de Emmanuel Lévinas. As autoras mostram como desinstitucionalização é um termo que se presta a mais de uma interpretação: desospitalização, desassistência ou desconstrução sendo apenas esta última a adequada às premissas e projetos inscritos no ideário da Reforma. Essa adequação está no fato de a desconstrução da cultura manicomial implicar uma transformação radical dos pressupostos nos quais se baseia a aproximação à loucura moldada nos últimos séculos no Ocidente, marcada pelo racionalismo na definição do sujeito, pela abordagem tecnocientífica do sofrimento e pela lógica de exclusão social e simbólica da diferença exibida pela experiência dos loucos.

O movimento antimanicomial é uma das formas de luta contra a exclusão e a favor da tolerância e respeito pela diferença. Neste sentido, a abordagem de Lévinas ilumina um aspecto fundamental do projeto reformista, que o caracteriza em relação a outros movimentos de ampliação do campo da cidadania. Como salientam as autoras, na perspectiva levinasiana a alteridade é pensada de forma radical, como diferença inassimilável e irredutível. O "Outro" - figura multiforme desta alteridade - não é um pólo em relação ao qual o eu possa entrar em sintonia, num movimento de aproximação que reduziria a assimetria inicial. O Outro, para Lévinas, é o radical e essencialmente diferente, o desconhecido, o estranho, o estrangeiro, o inimigo, o não-representável, o que não sou, não experimento, não imagino. O Outro é a exterioridade radical, irredutível e inabsorvível, mas que - por sua própria exterioridade - se revela como fundamental para a própria constituição e sustentação da experiência do 
mim-mesmo. A relação com o Outro, neste sentido, é fundante e conclama o mim-mesmo à responsabilidade por tudo aquilo que, não sendo idêntico a ele, o constitui e sustenta.

A loucura é uma das figurações desse Outro. Portanto, uma proposta inspirada nas proposições levinasianas não pode se restringir à denúncia de exclusão cultural do louco e à defesa de seus direitos civis, sociais e políticos. Ela precisa se apoiar numa reconfiguração profunda da relação com a alteridade radical, o Outro. Essa reconfiguração molda de maneira diferente nossa própria experiência subjetiva, na medida em que este Outro se expressa não apenas na experiência do louco, mas também nas fímbrias, desvãos e mistérios que habitam a experiência de todos nós. Esta perspectiva teórica, portanto, amplia o alcance ético e político contido nas propostas da Reforma, uma vez que seu horizonte ultrapassa os limites da simples assimilação do louco à realidade social compartilhada, projetando uma transformação profunda de nossas concepções e relações com a subjetividade.

Ultrapassada a fase de resistência e proposições alternativas, o projeto reformista encontra-se de certo modo numa encruzilhada: ou aprofunda seu movimento - deixando claro seu horizonte ético e seu projeto de transformação social e subjetiva -, ou corre o risco de deixar-se atrair pela força quase irresistível da burocracia e da institucionalização conservadora.

Os artigos aqui publicados, pelos temas que abordam e pela perspectiva que adotam, certamente contribuem para o diagnóstico e o enfrentamento dos desafios que encontramos na construção de uma sociedade que deixe para trás a história da cultura manicomial.

\section{NOTA}

- Psiquiatra, doutor em Saúde Coletiva pelo Instituto de Medicina Social da UERJ; professor adjunto no Departamento de Políticas e Instituições de Saúde do IMS-UERJ; membro da direção do Instituto Franco Basaglia. Endereço eletrônico: benilton@ superig.com.br. 